\title{
Policing Heteronormativity and Sexual Risk-Taking Among Young Adult Men Who Have Sex with Men in the Detroit Metro Area
}

\author{
Steven Meanley ${ }^{1,2}$. $\cdot$ James E. Egan ${ }^{3,4}$. José A. Bauermeister ${ }^{1,2}$
}

Published online: 23 August 2018

(c) Springer Science+Business Media, LLC, part of Springer Nature 2018

\begin{abstract}
Policing gender and sexuality can have enduring health implications for the well-being of young men who have sex with men (YMSM). Using data from a community-based sample of YMSM in the Detroit Metro Area $(\mathrm{N}=364)$, we examined the prevalence of lifetime heteronormative policing by gender (e.g., punished/restricted for femininity) and sexuality (e.g., attempts to alter same-sex attractions). We examined the associations of heteronormative policing attempts and the number of condomless insertive and receptive anal intercourse partners, respectively. We also tested whether internalized homophobia moderated the association between sexuality policing and sexual risk. Multivariable models demonstrated that policing sexuality, but not gender, was associated with a greater number of partners in which participants engaged in condomless intercourse as the receptive partner. We observed no interaction between policing sexuality and internalized homophobia. Multilevel efforts are needed to reduce the contribution of heteronormative policing on YMSM's HIV risk.
\end{abstract}

Keywords Heterosexism $\cdot$ Internalized homophobia $\cdot$ Gay and bisexual men $\cdot$ Condomless sex $\cdot$ Youth

\section{Resumen}

La vigilancia heteronormativa puede afectar el bienestar de los hombres jóvenes que tienen sexo con hombres (YMSM). Utilizando datos de una muestra comunitaria en el área metropolitana de Detroit $(\mathrm{N}=364)$, examinamos la prevalencia de vigilancia heteronormativa de género (e.j., castigado/restringido por mostrar feminidad) y sexualidad (e.j., intentos de alterar las atracciones entre personas del mismo sexo). Examinamos la asociación de estos procesos con el número de parejas sexuales, tanto insertivas como receptivas, con quien tuvieron sexo anal sin condón. También examinamos si la homophobia internalizada moderaba esta asociación. Los modelos multivariables indicaron que la vigilancia heteronormativa de sexualidad, pero no de género, estaba asociada con el número de parejas de alto riesgo. No hubo evidencia de una interacción con homofobia internalizada. Se necesitan esfuerzos multinivel para reducir la contribución de la vigilancia heteronormativa en el bienestar psicosocial y el riesgo de VIH entre los YMSM.

Steven Meanley

smeanley@ nursing.upenn.edu

1 Department of Family and Community Health, University of Pennsylvania School of Nursing, Philadelphia, PA, USA

2 Program on Sexuality, Technology \& Action Research, University of Pennsylvania School of Nursing, Philadelphia, PA, USA

3 Department of Behavioral and Community Health Sciences, University of Pittsburgh Graduate School of Public Health, Pittsburgh, PA, USA

4 The Center for LGBT Health Research, University of Pittsburgh Graduate School of Public Health, Pittsburgh, PA, USA

\section{Introduction}

Young adult men who have sex with men (YMSM; ages 18-29 years) remain a priority population for HIV prevention efforts given their continued disproportionate burden of HIV infection in the United States [1, 2]. HIV prevention experts acknowledge that thwarting the HIV epidemic in priority populations like YMSM requires efforts that address relevant psychosocial correlates of HIV such as internalized homophobia and enacted anti-gay stigma [3-5]. Internalized homophobia is defined as the inward projection of negative attitudes, beliefs, and stereotypes of sexual minorities (i.e., anti-gay stigma) into one's self-concept $[6,7]$. The association between internalized homophobia and sexual risk 
has demonstrated conflicting results [6, 7]; however, HIV prevention experts argue that exploration of this construct warrants further investigation where anti-gay stigma is especially salient [8].

Common manifestations of anti-gay stigma include societal heteronormative policing practices, which consist of overt efforts to monitor individuals' conformity to gender and sexuality norms through often-hostile forms of punishment (e.g., social isolation or exclusion, bullying, punishment, and professional assistance) [9]. These efforts are typically aimed at those who possess characteristics or express their gender and sexuality in ways that fall outside of what is considered socially acceptable by their communities. Messages that reinforce heteronormativity increase YMSM's vulnerability to psychological distress, particularly for men who express traditionally feminine interests or behaviors [9]. For example, prior research has noted that deviations from traditional masculinity norms are associated with MSM's risk-taking behaviors and well-being [10-12]. In a recent study, YMSM who experienced gender policing (e.g., punished for feminine behavior, sought counseling for femininity) by a parent or guardian reported greater substance use and psychological distress compared to those who did not [13]. To our knowledge, however, little is understood regarding how overt efforts to police gender and sexuality are associated with sexual risk-taking among YMSM.

YMSM may also experience social pressures to conform to society's value of heterosexual relationships over same-sex relationships. At present, there is limited research examining how attempts to alter one's sexual attractions are associated with health and well-being among young adult MSM. These practices, often mislabeled as therapeutic resources by anti-gay organizations, are commonly referred to as sexual reorientation, reparative, or conversion therapies [14]. Studies examining the efficacy of practices that attempt to modify sexual attractions have yielded little to no success, with those that have suggested success having been criticized for major methodological flaws $[15,16]$. Even fewer studies have assessed the health and behavioral outcomes associated with attraction modification attempts [11, 17]. In a prior qualitative study exploring health outcomes postattraction modification attempts, lesbian, gay, and bisexual adults described experiences of depression, suicidality, internalized homophobia, decreased self-esteem, distorted perceptions of homosexuality, sexual dysfunction, heightened awareness of gender non-conformity, loneliness, and social isolation [11]. Since these practices remain legal in most of the United States despite being considered harmful and dangerous, it is critical to better understand the magnitude in which attraction modification attempts are associated with poor health outcomes.

MSM are exposed to heteronormative messaging aimed at policing both masculinity and sexuality within their interpersonal networks, particularly in adolescence and young adulthood $[9,18]$. While growing up in anti-gay stigmatizing environments, many YMSM experience the stress of realizing, navigating, and integrating their same-sex attractions into their self-concepts given conflicts with their heteronormative beliefs perpetuated by their social communities [19]. For youth and young adults, interpersonal contexts provide a social resource for perceptions of community attitudes on gender and sexuality norms [20]. Prior research suggests that the well-being of YMSM is compromised when negative reactions arise upon disclosing nonheteronormative traits like same-sex attractions [21, 22].

To our knowledge, no study has examined the association between heteronormative policing variables and sexual-risk taking among YMSM. As a correlate of sexual risk, internalized homophobia may inform the association between heteronormative policing and YMSM's sexual risk behaviors. In fact, one prior review suggests that internalized homophobia may interact with other predictors of sexual risk, like stigma, to shape sexual risk behaviors; specifically, experiences of anti-gay stigma may exacerbate the association between latent internalized homophobia and sexual risk [6]. Therefore, our research study addresses how heteronormative policing, as marginalizing experiences in childhood and young adulthood interact with internalized homophobia to increase the vulnerability of young adult MSM to HIV [14].

Our study has three objectives. Our first aim was to describe the prevalence and characterize YMSM's heteronormative policing experiences-specifically, lifetime practice-based attraction modification attempts (LPAMA) and parent/guardian gender policing (PGGP). Our second aim was to test the main associations between sexual risktaking, YMSM's experiences of internalized homophobia, and both heteronormative policing experiences, respectively. We hypothesized that increases in internalized homophobia would be associated with an increase in sexual risk-taking. We also hypothesized that independently, experiences of LPAMA and PGGP would be associated with an increase in YMSM's sexual risk behaviors. For our last aim, we sought to assess whether LPAMA moderated the relationship between internalized homophobia and sexual risk taking among YMSM. Given the non-sexuality affirming nature of attraction modification practices, we hypothesized that there would be an interaction between experiences of attraction modification attempts and internalized homophobia on sexual risk; specifically, young adult MSM who report LPAMA and high scores of internalized homophobia would report greater sexual risk-taking than those who report no LPAMA and low internalized homophobia. 


\section{Methods}

Participants for this study completed a web-based survey for a cross-sectional, observational study developed to better understand young adult MSM's structural and psychosocial vulnerabilities to HIV/AIDS in the Detroit Metropolitan Area. We recruited 397 YMSM through advertisements both online (Black Gay Chat and Facebook) as well as in-person at Detroit area gay bars, clubs, and LGBT youth-specific community events [23, 24]. Participants were eligible if they were between 18 and 29 years of age, identified as cis-male, a resident of the Detroit Metro Area (verified by zip code and IP address), and report ever having had sex with a man. YMSM who completed our web-based survey were compensated a $\$ 30$ Visa e-gift card for their time. For our analysis, we used listwise deletion to remove cases with incomplete responses to our battery of survey items given the small percentage $(8.3 \%)$ and since most of the missing responses are observed in variables treated as covariates [25]. Participants with missing responses were more likely to selfreport as HIV-positive than HIV-negative $\left(\chi_{d f=1}^{2}=6.24\right.$, $p=0.012$ ). Our final analytic sample includes 364 YMSM.

\section{Procedures}

Prior to the starting the web-based survey, participants were screened and provided consent to participate electronically. Informed consent was obtained from all individual participants included in the study. Upon consent, participants completed a 45-60 min questionnaire that assessed sociodemographic characteristics, self-reported HIV status, individual-level outcomes (e.g., psychological well-being, substance use, and sexual behaviors), community-level perceptions and experiences (e.g., stigma, social networks), and resiliency measures (e.g., hopes and dreams, social support, and life purpose). All study procedures were approved by the University of Michigan Institutional Review Board.

\section{Measures}

\section{Parental/Guardian Gender Policing (PGGP)}

Participants were asked to indicate whether or not their parent(s) or person(s) who raised them ever told them to stop acting feminine or restricted/punished them for acting feminine in their lifetime $(0=$ No, $1=$ Yes $)$.
Lifetime Practice-Based Attraction Modification Attempts (LPAMA)

Participants were asked a single, dichotomous item of whether or not they had ever seen a counselor/pastor/ clergy who tried to change who they were attracted to in their lifetime $(0=$ No, $1=$ Yes $)$.

\section{Heteronormative Policing Groups}

To examine the collinearity between LPAMA and PGGP, we created a composite variable based on YMSM's responses to LPAMA and PGGP. The 4 categories were: $0=$ Neither PGGP nor LPAMA, $1=$ PGGP Only, $2=$ LPAMA Only, and $4=$ Both PGGP and LPAMA.

\section{Internalized Homophobia}

Participants provided responses to a validated 9-item scale for internalized homophobia [26]. Example items included, "I wish I could develop more erotic feelings about women," and "I have tried to become more sexually attracted to women." These nine items were scored using a 4-point Likert scale and summed to reflect greater internalized homophobia for higher scores $(0=$ strongly disagree, $3=$ strongly agree; range 0 to 27). Our scale for internalized homophobia exhibited very high internal consistency (Cronbach's $\alpha=0.92$ ).

\section{Sexual Risk: Number of Condomless Anal Intercourse (CAI) Partners}

We developed two indicators of sexual risk-taking using two items presented formally and colloquially. For condomless insertive anal intercourse (CIAI), participants were asked, "In the past 30 days, into how many men's rectums did you put your penis without a condom?" (How many men did you fuck in the ass without a condom?). For condomless receptive anal intercourse (CRAI), we asked, "In the past 30 days, how many men put their penises in your rectum without a condom?" (How many men fucked you in the ass without a condom?). Data were collected prior to PrEP implementation in Detroit; thus, our CAI measures are appropriate indicators of HIV risk behavior.

\section{Sociodemographic Characteristics}

We used standard measures assessing participants' age, sexual identity $(0=$ gay, $1=$ bisexual, $2=$ other MSM identity $)$, race/ethnicity $(0=$ Non-Hispanic Black, $1=$ Non-Hispanic Black, $2=$ Hispanic/Latino all races, $3=$ other and multiple 
race/ethnicities $)$, self-reported HIV status $(0=$ negative, $1=$ positive, $2=$ unknown $)$, and income $(0=$ above federal poverty line, $1=$ below federal poverty line [27].

\section{Data Analytic Strategies}

To characterize experiences of heteronormative policing, we performed bivariate tests of association to distinguish those who reported no policing, PGGP only, LPAMA only, and both types of policing by sample characteristics. We performed a series of unadjusted Poisson models, regressing heteronormative policing, internalized homophobia, and sociodemographic variables on the number of CRAI and CIAI partners, respectively. Statistically significant associations and theoretically-relevant variables (e.g., race/ethnicity, sexual identity, HIV status, and poverty) were included in our models. We developed multivariable Poisson models to examine the associations of heteronormative policing variables and internalized homophobia for both sexual risk outcomes, adjusting for sociodemographic characteristics. Lastly, we assessed whether the association of LPAMA on the number of CRAI and CIAI partners varied across levels of internalized homophobia (interaction). Consequently, we included both heteronormative policing variables as independent predictors in our regression models.

\section{Results}

\section{Sample Characteristics}

Descriptive statistics by heteronormative policing groups are provided in Table 1. The average age of our sample was 23.11 years $(\mathrm{SD}=2.84)$. Participants predominantly identified as gay/homosexual (84.1\%) with smaller numbers of bisexual (8.2\%) and other sexual identity (7.7\%). About half (48.9\%) identified as Non-Hispanic Black, $28 \%$ as Non-Hispanic White, $7.4 \%$ as Hispanic/Latino, and $15.7 \%$ as Other Race/Ethnicity. There were $9.3 \%$ who self-reported being HIV-positive and $10.7 \%$ reported an unknown serostatus. Nearly half (45.6\%) of participants reported income below the federal poverty line.

With respect to heteronormative policing, $37.1 \%$ reported any PGGP and $11.3 \%$ reported any LPAMA. When broken down by heteronormative policing group, $59.3 \%$ reported neither PGGP nor LPAMA, 29.4\% reported PGGP only, $3.6 \%$ reported LPAMA only, and $7.7 \%$ reported both PGGP and LPAMA. Those who reported LPAMA (68.3\%) were also more likely to report PGGP $(\varphi=0.23, p<0.001)$ than those who did not (33.1\%). There were no statistically significant associations between heteronormative policing groups and sociodemographic characteristics.

\section{Internalized Homophobia}

The mean internalized homophobia score in our sample was $5.48(\mathrm{SD}=6.04$; range $=0-27)$. Our analysis (Table 2$)$ exhibited that Non-Hispanic Black participants $(m=6.94$, $\mathrm{SD}=6.17)$ reported greater internalized homophobia compared to Non-Hispanic White $(m=4.03, \mathrm{SD}=5.36$, $p<0.001)$ and men who identified with Other/Multiple racial identities $(m=3.63, \mathrm{SD}=5.01, p=0.001)$. Gayidentified YMSM $(m=4.92, \mathrm{SD}=5.75)$ reported less internalized homophobia compared to bisexual identified men $(m=9.57, \mathrm{SD}=9.57, p<0.001)$. Lastly, YMSM who reported any LPAMA $(m=5.05, \mathrm{SD}=5.69)$ exhibited greater internalized homophobia compared to those who reported none $(m=8.90, \mathrm{SD}=7.57, p<0.001)$. We observed no other statistically significant differences in internalized homophobia by HIV status, education level, income, or PGGP.

\section{Number of Condomless Insertive Anal Intercourse Partners}

Participants in our study reported a range of 0-15 CIAI partners in the past 30 days. In unadjusted models (Table 3), age $(\operatorname{IRR}=1.12,95 \%$ CI 1.03, 1.21, $p=0.006)$ and internalized homophobia $(\operatorname{IRR}=1.04,95 \%$ CI 1.01, $1.08, p=0.008)$ were associated with a greater number of CIAI partners in the past 30 days. We observed no statistically significant unadjusted relationships between PGGP, other sociodemographic characteristics, and participants' number of CIAI partners.

Though LPAMA approached significance at the unadjusted level (IRR $=1.78,95 \%$ CI $0.98,3.24, p=0.058$ ), it did not emerge to be significantly associated with number of CIAI partners in multivariable analyses. Age (IRR $=1.13$, 95\% CI 1.01, 1.27, $p=0.039$ ) and internalized homophobia $(\mathrm{IRR}=1.03,95 \% \mathrm{CI} 1.01,1.06, p=0.046)$ remained associated with number of CIAI partners. In our interaction model, we observed no moderating effect of LPAMA on the association between internalized homophobia and CIAI partners.

\section{Number of Condomless Receptive Anal Intercourse Partners}

Participants in our study reported a range of 0-15 CRAI partners in the past 30 days. In unadjusted models (Table 4), participants who reported a Hispanic/Latino ethnicity $(\mathrm{IRR}=0.40,95 \%$ CI $0.18,0.89, p=0.025) \mathrm{had}$ a fewer number of CRAI partners compared to NonHispanic Blacks. LPAMA was statistically significantly associated with an increase the number of CRAI partners $($ IRR $=2.02,95 \%$ CI $1.14,3.59, p=0.016)$. No other 
Table 1 Characterizing heteronormative policing among YMSM

\begin{tabular}{|c|c|c|c|c|c|c|c|}
\hline \multirow{2}{*}{$\begin{array}{l}\text { Sociodemographic } \\
\text { characteristic }\end{array}$} & \multirow[t]{2}{*}{ Total sample $N=394$} & \multicolumn{4}{|c|}{ Heteronormative Policing Categories } & \multirow[t]{2}{*}{$F$ or $\chi^{2}$} & \multirow[t]{2}{*}{$p$} \\
\hline & & $\begin{array}{l}\text { Neither PGGP } \\
\text { nor LPAMA } \\
N=216\end{array}$ & PGGP only $N=107$ & LPAMA only $N=13$ & $\begin{array}{l}\text { PGGP and } \\
\text { LPAMA } \\
N=28\end{array}$ & & \\
\hline Age, m (SD) & $23.11(2.84)$ & $23.02(2.66)$ & $22.99(3.13)$ & $24.23(2.42)$ & $23.71(3.14)$ & 1.24 & 0.295 \\
\hline Race/ethnicity, N (\%) & & & & & & 5.57 & 0.782 \\
\hline Non-hispanic black & $178(48.9)$ & $102(57.3)$ & $54(30.3)$ & $9(5.1)$ & $13(7.3)$ & & \\
\hline Non-hispanic white & $102(28.0)$ & $65(63.7)$ & $29(28.4)$ & $2(2.0)$ & $6(5.9)$ & & \\
\hline $\begin{array}{l}\text { Hispanic/latino all } \\
\text { races }\end{array}$ & $27(7.4)$ & $17(63.0)$ & $8(29.6)$ & $0(0.0)$ & $2(7.4)$ & & \\
\hline Other/multiple races & $57(15.7)$ & $32(56.1)$ & $16(28.1)$ & $2(3.5)$ & $7(12.3)$ & & \\
\hline Sexual identity, N (\%) & & & & & & 6.73 & 0.347 \\
\hline Gay & $306(84.1)$ & $182(59.5)$ & $92(30.1)$ & $10(3.3)$ & $22(7.2)$ & & \\
\hline Bisexual & $30(8.2)$ & $18(60.0)$ & $7(23.3)$ & $3(10.0)$ & $2(6.7)$ & & \\
\hline Other MSM identity & $28(7.7)$ & $16(57.1)$ & $8(28.6)$ & $0(0.0)$ & $4(14.3)$ & & \\
\hline HIV status, N (\%) & & & & & & 10.56 & 0.103 \\
\hline Negative & 291 (79.9) & $171(58.8)$ & $91(31.3)$ & $9(3.1)$ & $20(6.9)$ & & \\
\hline Positive & $34(9.3)$ & $18(52.9)$ & $7(20.6)$ & $3(8.8)$ & $6(17.6)$ & & \\
\hline Unaware & $39(10.7)$ & $27(69.2)$ & $9(23.1)$ & $1(2.6)$ & $2(5.1)$ & & \\
\hline Education level, N (\%) & & & & & & 5.22 & 0.156 \\
\hline $\begin{array}{l}\text { High school/GED or } \\
\text { less }\end{array}$ & $116(31.9)$ & $70(60.3)$ & 39 (33.6) & $2(1.7)$ & $5(4.3)$ & & \\
\hline More than HS/GED & $248(68.1)$ & $146(58.9)$ & $68(27.4)$ & $11(4.4)$ & $23(7.7)$ & & \\
\hline Poverty (income), N (\%) & & & & & & 0.78 & 0.854 \\
\hline $\begin{array}{l}\text { Above federal poverty } \\
\text { line }\end{array}$ & $198(54.4)$ & $119(60.1)$ & $55(27.8)$ & $8(4.0)$ & $16(8.1)$ & & \\
\hline $\begin{array}{l}\text { Below federal poverty } \\
\text { line }\end{array}$ & $166(45.6)$ & $97(58.4)$ & $52(31.3)$ & $5(3.0)$ & $12(7.2)$ & & \\
\hline $\begin{array}{l}\text { Internalized homopho- } \\
\text { bia (IHOM), m (SD)* }\end{array}$ & $1.61(0.67)$ & $1.55(0.62)$ & $1.59(0.67)$ & $2.15(0.99)$ & $1.92(0.77)$ & 5.44 & 0.001 \\
\hline $\begin{array}{l}\text { Condomless insertive } \\
\text { anal intercourse part- } \\
\text { ners, m (SD) }\end{array}$ & $0.39(1.03)$ & $0.40(1.19)$ & $0.26(0.56)$ & $0.54(0.66)$ & $0.68(1.22)$ & 1.39 & 0.247 \\
\hline $\begin{array}{l}\text { Condomless recep- } \\
\text { tive anal intercourse } \\
\text { partners, m (SD) }\end{array}$ & $0.50(1.21)$ & $0.46(1.34)$ & $0.42(0.69)$ & $0.62(0.65)$ & $1.04(1.73)$ & 2.12 & 0.097 \\
\hline
\end{tabular}

LPAMA Only Group had higher IHOM compared to PGGP only ( $m$ diff. $=0.56, p=0.022$ ); Compared to the Neither PGGP/LPAMA Group, LPAMA Only ( $m$ diff. $=0.59, p=0.010$ ) and Both PGGP/LPAMA ( $m$ diff. $=0.36, p=0.032$ ) groups reported higher IHOM

variables were statistically significantly associated with CRAI partners in unadjusted models.

In our multivariable Poisson model adjusting for race/ethnicity, sexual identity, and HIV status, LPAMA remained associated with an increase in the number of CRAI partners (IRR $=1.84,95 \%$ CI 1.02, 3.34, $p=0.044$ ). Internalized homophobia and PGGP were not associated with number of CRAI partners. Lastly, we observed no statistically significant interaction between LPAMA and internalized homophobia on CRAI.

\section{Discussion}

Our study explored how heteronormative policing practices are associated with young adult MSM's sexual risktaking. A substantial proportion of YMSM in our sample reported experiencing heteronormative policing practices, with over a third of our sample reported PGGP in their lifetime and over $10 \%$ of YMSM reported being subjected to practice-based attraction modification attempts. 
Table 2 Mean scores in internalized homophobia by sociodemographic characteristics and heteronormative policing

\begin{tabular}{|c|c|c|c|}
\hline \multirow[t]{2}{*}{ Sociodemographic characteristic } & \multicolumn{3}{|c|}{ Internalized homophobia } \\
\hline & $m(\mathrm{SD})$ & $t$ or $F$ & $p$ \\
\hline Race/ethnicity, N (\%) & & 7.60 & 0.001 \\
\hline Non-hispanic black & $6.94(6.17)$ & & \\
\hline Non-hispanic white & $4.03(5.36)$ & & \\
\hline Hispanic/latino & $5.30(7.29)$ & & \\
\hline All other/multiple races & $3.63(5.01)$ & & \\
\hline Sexual identity, N (\%) & & 9.90 & 0.001 \\
\hline Gay & $4.92(5.75)$ & & \\
\hline Bisexual & $9.57(7.26)$ & & \\
\hline Other MSM identity & $7.29(5.86)$ & & \\
\hline HIV status, $\mathrm{N}(\%)$ & & 0.17 & 0.848 \\
\hline Negative & $5.41(5.73)$ & & \\
\hline Positive & $5.52(6.59)$ & & \\
\hline Unaware & $6.00(7.74)$ & & \\
\hline Education level, N (\%) & & 0.39 & 0.698 \\
\hline High school/GED or less & $5.66(6.38)$ & & \\
\hline More than HS/GED & $5.40(5.89)$ & & \\
\hline Poverty (income), N (\%) & & -0.36 & 0.718 \\
\hline Above federal poverty line & $5.38(6.02)$ & & \\
\hline Below federal poverty line & $5.61(6.08)$ & & \\
\hline \multicolumn{4}{|l|}{ Parental/guardian } \\
\hline Gender policing (PGGP) & & -0.95 & 0.344 \\
\hline None & $5.25(5.90)$ & & \\
\hline Any & $5.87(6.28)$ & & \\
\hline \multicolumn{4}{|l|}{ Lifetime practice-based attraction } \\
\hline Modification attempts (LPAMA) & & -3.92 & $<0.001$ \\
\hline None & $5.05(5.69)$ & & \\
\hline Any & $8.90(7.57)$ & & \\
\hline
\end{tabular}

Pearson's Correlation for age and internalized homophobia is $r=0.01$ $(p=0.963)$

Developed to alter individual's same-sex attractions, practice-based attraction modification attempts are rooted in historical attitudes that sought to classify homosexuality as sinful, criminal, and as a mental illness [28, 29]. Though homosexuality has been declassified as a mental illness for decades, many communities that uphold anti-gay beliefs also believe that sexual attractions are alterable [30]. To accomplish this, a number of different methods exist aimed at altering, suppressing, or "curing" sexual minorities of their same-sex attractions including 1-on-1 counseling, prayer/religion-based therapies, electric shock therapy, and gender role reinforcement (e.g., being encouraged to engage in heterosexual relationships; [13, 31, 32]. Given that attraction modification practices are deemed dangerous and ineffective to the well-being of sexual minorities by prominent academic/professional institutions like the American Medical Association, American Psychological
Association, and the National Association of Social Workers [33], the high prevalence of modification attempts is alarming.

As hypothesized, reporting heteronormative policing on sexual attraction was linked to HIV risk behaviors among our sample of YMSM. Our findings indicated that LPAMA was associated with an increase in number of condomless anal intercourse partners among YMSM who engaged in the receptive role. This is significant given that there is much greater risk of HIV transmission for receptive partners compared to those who engaged in condomless anal intercourse as the insertive partner [34]. These findings support prior literature that has demonstrated how antigay stigma increases YMSM's vulnerability to HIV, that non-affirming experiences are associated with sexual risk behaviors [35].

We observed no significant moderation of internalized homophobia on the relationship between LPAMA and number of sexual risk partners for men engaging in either receptive or insertive position. Internalized homophobia, however, was independently and positively associated with the number of sexual risk partners in YMSM engaging in the insertive sexual position. These findings may reflect the body of literature that describes an interconnected relationship between internalized homophobia and cultural expectations of masculinity [36]. Specifically, for some YMSM, internalized homophobia may be in part due to unreconciled beliefs that same-sex attractions do not conform to cultural definitions of masculinity [12]. This in turn, shapes sexual decision making, particularly around sexual positioning and linking masculinity to the insertive sexual role [36, 37]. Furthermore, prior reports have demonstrated sexual risk among YMSM who endorse traditional attitudes toward masculinity [38].

We hypothesized that PGGP would be associated with increased sexual risk among YMSM, yet this hypothesis was unsupported. Although prior research has linked expectations of masculinity to HIV risk among samples of YMSM [39-41], it is possible that our null findings are attributable to how we measured PGGP. Our measure was unable to assess salience, duration, and type/severity of these practices on the health and well-being of young adult MSM. Developing psychometrically sound measures for future surveillance that adequately captures PGGP would yield greater depth and quality for assessing the association of heteronormative policing's on sexual risk. With our measurement of PGGP, we were also unable to distinguish contradicting experiences (e.g., affirming versus non-affirming) that may have been displayed by different parents (e.g., mother versus father) or guardians, which warrants further analysis. This is especially important given that prior research indicates father figures tend to enforce gender norms compared to mother figures [42]. 
Table 3 Unadjusted and adjusted poisson models of condomless insertive anal intercourse partners among young adult men who have sex with men, $\mathrm{N}=364$

\begin{tabular}{|c|c|c|c|c|c|c|c|c|c|}
\hline \multirow[t]{2}{*}{ Variables } & \multicolumn{3}{|c|}{ Unadjusted models } & \multicolumn{3}{|c|}{ Adjusted model 1a } & \multicolumn{3}{|c|}{ Adjusted Model 1b } \\
\hline & IRR & $95 \% \mathrm{CI}$ & $p$ & IRR & $95 \% \mathrm{CI}$ & $p$ & IRR & $95 \% C I$ & $p$ \\
\hline Age & 1.12 & $1.03,1.21$ & 0.006 & 1.13 & $1.01,1.27$ & 0.039 & 1.13 & $1.01,1.27$ & 0.041 \\
\hline \multicolumn{10}{|l|}{ Race/ethnicity } \\
\hline Black/African-American & REF & & & REF & & & REF & & \\
\hline White/caucasian & 0.68 & $0.36,1.29$ & 0.240 & 0.79 & $0.46,1.37$ & 0.409 & 0.80 & $0.46,1.38$ & 0.421 \\
\hline Hispanic/latino—all races & 1.20 & $0.63,2.27$ & 0.577 & 1.22 & $0.66,2.25$ & 0.522 & 1.25 & $0.67,2.33$ & 0.480 \\
\hline Other/multiple races & 0.81 & $0.43,1.52$ & 0.515 & 1.11 & $0.66,1.89$ & 0.700 & 1.14 & $0.67,1.93$ & 0.629 \\
\hline \multicolumn{10}{|l|}{ Sexual identity } \\
\hline Gay/homosexual & REF & & & REF & & & REF & & \\
\hline Bisexual & 2.19 & $0.61,7.84$ & 0.227 & 1.95 & $0.56,6.80$ & 0.293 & 1.94 & $0.56,6.68$ & 0.295 \\
\hline Other MSM identity & 1.12 & $0.44,2.89$ & 0.809 & 1.01 & $0.42,2.44$ & 0.975 & 1.03 & $0.43,2.48$ & 0.948 \\
\hline \multicolumn{10}{|l|}{ HIV status } \\
\hline Negative & REF & & & REF & & & REF & & \\
\hline Positive & 1.45 & $0.69,3.08$ & 0.329 & 1.08 & $0.49,2.38$ & 0.856 & 1.11 & $0.51,2.43$ & 0.801 \\
\hline Unaware & 1.20 & $0.59,2.43$ & 0.619 & 1.14 & $0.52,2.48$ & 0.741 & 1.13 & $0.52,2.47$ & 0.752 \\
\hline \multicolumn{10}{|l|}{ Education level } \\
\hline HS/GED or less & REF & & & & & & & & \\
\hline More than HS/GED & 0.97 & $0.47,1.98$ & 0.924 & & & & & & \\
\hline \multicolumn{10}{|l|}{ Poverty } \\
\hline Above federal poverty line & REF & & & & & & & & \\
\hline Below federal poverty line & 0.72 & $0.37,1.38$ & 0.320 & & & & & & \\
\hline Internalized homophobia & 1.04 & $1.01,1.08$ & 0.008 & 1.03 & $1.01,1.06$ & 0.046 & 1.04 & $1.01,1.08$ & 0.040 \\
\hline \multicolumn{10}{|l|}{ LPAMA } \\
\hline None & REF & & & REF & & & REF & & \\
\hline Any & 1.78 & $0.98,3.24$ & 0.058 & 1.43 & $0.66,3.17$ & 0.362 & 1.59 & $0.75,3.39$ & 0.227 \\
\hline \multicolumn{10}{|l|}{ PGGP } \\
\hline None & REF & & & REF & & & REF & & \\
\hline Any & 0.85 & $0.51,1.42$ & 0.533 & 0.75 & $0.46,1.22$ & 0.247 & 0.74 & $0.45,1.22$ & 0.232 \\
\hline Internalized homophobia*LPAMA & & & & & & & 0.98 & $0.92,1.04$ & 0.412 \\
\hline
\end{tabular}

Our analysis has several additional limitations. First, the prevalence of LPAMA and PGGP among YMSM may be underestimated due to social desirability and/or the eligibility criteria of our study. Given that YMSM had to be sexually active to be eligible in our study, it is unclear whether the proportion of LPAMA and PGGP is comparable among YMSM who have not had their sexual debut. Future research should seek to understand how heteronormative policing behaviors are linked to YMSM's sexual debuts and subsequent sexual risk-taking. Second, our results may also underestimate the relationship between heteronormative policing and HIV serostatus since HIV-positive participants were more likely to provide incomplete responses than HIV-negative men. Future research should further explore the relationship between heteronormative policing and HIV seroconversion given its relationships with psychosocial correlates of HIV and condomless receptive anal sex $[11,13]$. Third, the cross-sectional nature of our study limits our ability to make causal statements about the relationships assessed on our analyses. Retrospective study designs examining heteronormative policing by age or generation cohorts may further explicate how these stigmatizing experiences shape health behaviors (e.g., sexual risk), outcomes (e.g., HIV), and wellbeing among MSM populations across the life course.

Lastly, the current study assessed a community-based sample of YMSM's social and structural vulnerabilities to HIV in the Detroit Metropolitan Area; therefore, our findings are not generalizable to populations beyond our sample. Future efforts may benefit from exploring the multifaceted nature of these practices by diverse populations of sexual and gender minorities (e.g., sexual minority women and transgender communities) including those who have not had their sexual debut. Lastly, retrospective study designs examining heteronormative policing by age or generation cohorts may further seek to contextualize how these stigmatizing experiences shape health behaviors (e.g., sexual 
Table 4 Unadjusted and adjusted poisson models of condomless receptive anal intercourse partners among young adult men who have sex with men, $\mathrm{N}=364$

\begin{tabular}{|c|c|c|c|c|c|c|c|c|c|}
\hline \multirow[t]{2}{*}{ Variables } & \multicolumn{3}{|c|}{ Unadjusted models } & \multicolumn{3}{|c|}{ Adjusted model 1a } & \multicolumn{3}{|c|}{ Adjusted model $1 \mathrm{~b}$} \\
\hline & IRR & $95 \% \mathrm{CI}$ & $p$ & IRR & $95 \% \mathrm{CI}$ & $p$ & IRR & $95 \% \mathrm{CI}$ & $p$ \\
\hline Age & 1.03 & $0.93,1.14$ & 0.621 & & & & & & \\
\hline \multicolumn{10}{|l|}{ Race/ethnicity } \\
\hline Black/African-American & REF & & & REF & & & REF & & \\
\hline White/caucasian & 0.73 & $0.42,1.27$ & 0.264 & 0.75 & $0.44,1.28$ & 0.290 & 0.75 & $0.44,1.29$ & 0.299 \\
\hline Hispanic/latino-all races & 0.40 & $0.18,0.89$ & 0.025 & 0.42 & $0.19,0.93$ & 0.032 & 0.43 & $0.19,0.95$ & 0.036 \\
\hline Other/multiple races & 1.15 & $0.58,2.28$ & 0.695 & 1.09 & $0.60,1.96$ & 0.779 & 1.10 & $0.61,1.97$ & 0.751 \\
\hline \multicolumn{10}{|l|}{ Sexual identity } \\
\hline Gay/homosexual & REF & & & REF & & & REF & & \\
\hline Bisexual & 1.62 & $0.45,5.77$ & 0.458 & 1.48 & $0.44,4.98$ & 0.532 & 1.48 & $0.44,4.96$ & 0.530 \\
\hline Other MSM identity & 0.98 & $0.47,2.03$ & 0.956 & 0.90 & $0.45,1.80$ & 0.768 & 0.91 & $0.45,1.81$ & 0.784 \\
\hline \multicolumn{10}{|l|}{ HIV status } \\
\hline Negative & REF & & & REF & & & REF & & \\
\hline Positive & 1.65 & $0.82,3.29$ & 0.158 & 1.35 & $0.67,2.74$ & 0.400 & 1.37 & $0.67,2.82$ & 0.393 \\
\hline Unaware & 1.49 & $0.66,3.37$ & 0.336 & 1.62 & $0.71,3.72$ & 0.252 & 1.64 & $0.72,3.71$ & 0.238 \\
\hline \multicolumn{10}{|l|}{ Education level } \\
\hline HS/GED or less & REF & & & & & & & & \\
\hline More than HS/GED & 0.80 & $0.46,1.38$ & 0.417 & & & & & & \\
\hline \multicolumn{10}{|l|}{ Poverty } \\
\hline Above federal poverty line & REF & & & & & & & & \\
\hline Below federal poverty line & 1.03 & $0.62,1.73$ & 0.902 & & & & & & \\
\hline Internalized homophobia & 1.01 & $0.97,1.05$ & 0.719 & 0.99 & $0.96,1.02$ & 0.603 & 1.00 & $0.95,1.04$ & 0.848 \\
\hline \multicolumn{10}{|l|}{ LPAMA } \\
\hline None & REF & & & REF & & & & & \\
\hline Any & 2.02 & $1.14,3.59$ & 0.016 & 1.84 & $1.02,3.34$ & 0.044 & 1.90 & $1.08,3.34$ & 0.026 \\
\hline \multicolumn{10}{|l|}{ PGGP } \\
\hline None & REF & & & REF & & & REF & & \\
\hline Any & 1.17 & $0.73,1.89$ & 0.514 & 1.08 & $0.73,1.60$ & 0.704 & 1.07 & $0.72,1.60$ & 0.732 \\
\hline Internalized homophobia*LPAMA & & & & & & & 0.99 & $0.92,1.06$ & 0.709 \\
\hline
\end{tabular}

risk), outcomes (e.g., HIV), and well-being among MSM populations across the life course.

Taken together, our findings may inform interventions across multiple levels of the social ecological spectrum that aim to reduce exposure to heteronormative policing practices and affirm positive sexual identity development in YMSM. At the structural level, our findings support the need for continued legal and advocacy efforts seeking to ban religious and pseudo-scientific initiatives aimed to alter sexual minorities' sexual attractions. To date, only 11 states (CA, CT, IL, MD, NJ, NM, NV, OR, RI, VT, WA) and the District of Columbia prohibit licensed mental health professionals to practice methods that attempt to alter individuals' same-sex attractions [43]. In fact, organizations like the National Association for Research \& Therapy of Homosexuality (NARTH), continue to advocate for sexual reorientation therapies and non-secular/faith-based perspectives of male-female models of gender and sexuality [44].
In further support of banning these practices, a recent study exposed how the employment of many attraction modification practices (e.g., covert desensitization, self-harming techniques, non-autonomy) counter ethical guidelines for licensed mental health professionals [45]. The permissibility of these practices not only reinforces stigmatizing attitudes toward sexual minorities in the U.S, but also harms the well-being of these victims. Given the association between LPAMA and sexual risk-taking behaviors, successful efforts to prohibit these practices may support HIV prevention strategies for YMSM. In addition, while no standard of practice exists to treat individuals who have undergone LPAMA, mental health providers should seek to work with these clients to develop adaptive coping skills in the face of homophobic contexts and relationships [45].

Community efforts should continue to build on evidencebased practices seeking to reduce stigmatizing norms toward same-sex attracted individuals as well as individuals who do 
not conform to traditional gender roles. Interventions that communicate diversity have the potential to alter environmental cues to affirm members of marginalized communities [46]. Furthermore, given prior findings that indicate negative family reactions as a predictor of engaging in any LPAMA we advocate for the continued support of the development of family-based interventions that seek to reduce stigma arising from heteronormative belief systems [18]. Family rejection is a significant predictor of negative health outcomes in YMSM; thus, interventions that are able to build and enhance affirming social support from parents/guardians to their same-sex attracted and gender non-conforming youth may improve the psychosocial and sexual health of YMSM [47, 48].

Lastly, alongside addressing YMSM's internalized homophobia, individual-level psychosocial and sexual health interventions should address YMSM's experiences with heteronormative policing, the extent to which these experiences have had a negative impact on their lives, as well as relevant health concerns. Where appropriate, referral to psychological resources may be warranted.

Our findings support scientific organizations' arguments that parental and professional efforts that aim to alter samesex attractions are dangerous practices with respect to the psychosocial development of sexual minorities. Furthermore, we expand on prior literature arguing that these practices increase this population's vulnerability to HIV through engagement in condomless sex. Additional research examining how gender and sexuality policing are linked to YMSM's HIV risk correlates are warranted. Multilevel efforts that aim to reduce heteronormative policing may be pragmatic to thwarting the HIV epidemic in HIV prevention priority populations such as young adult MSM.

Acknowledgements We thank members of the United for HIV Integration and Policy (UHIP) community advisory board and the participants of the study for their important contributions in this research.

Funding This study was funded by the Ford Foundation and the MAC AIDS Fund to José A. Bauermeister. The content is solely the responsibility of the authors and does not necessarily represent the official views of the Ford Foundation or the MAC AIDS Fund.

\section{Compliance with Ethical Standards}

Conflicts of interest Steven Meanley declares that he has no conflicts of interest. James E. Egan declares that he has no conflicts of interest. José A. Bauermeister declares he has no conflicts of interest.

Ethical Approval All procedures performed in studies involving human participants were in accordance with the ethical standards of the institutional and/or national research committee and with the 1964 Helsinki declaration and its later amendments or comparable ethical standards.

Informed Consent Informed consent was obtained from all individual participants included in the study.

\section{References}

1. Balaji AB, Bowles KE, Le BC, Oster AM, for the NHBS Study Group. High HIV incidence and prevalence and associated factors among young MSM, 2008. AIDS. 2013;27(2):269-78.

2. Centers for Disease Control and Prevention. HIV among youth. https://www.cdc.gov/hiv/group/age/youth/index.html. Accessed 3 Aug 2017.

3. Baral S, Logie CH, Grosso A, Wirtz AL, Beyrer C. Modified social ecological model: a tool to guide the assessment of the risks and risk contexts of HIV epidemics. BMC Public Health. 2013;13:482-9.

4. Oldenburg CE, Perez-Brumer AG, Hatzenbuehler ML, Krakower D, Mimiaga MJ, Mayer KH. State-level structural sexual stigma and HIV prevention in a national online sample of HIVuninfected men who have sex with men in the United States. AIDS. 2015;29(7):837-45.

5. Halkitis PN. Reframing HIV prevention for gay men in the United States. Am Psychol. 2010;65(8):752-63.

6. Newcomb ME, Mustanski B. Moderators of the relationship between internalized homophobia and risky sexual behavior in men who have sex with men: a meta-analysis. Arch Sex Behav. 2011;40(1):189-99.

7. Szymanski DM, Kashubeck-West S, Meyer J. Internalized heterosexism: measurement, psychosocial correlates, and research directions. Couns Psychol. 2008;36(4):525-74.

8. Ross MW, Simon Rosser BR, Smolenski D. The importance of measuring internalized homophobia/homonegativity. Arch Sex Behav. 2010;39:1207-8.

9. Horn SS. Adolescents' acceptance of same-sex peers based on sexual orientation and gender expression. J Youth Adolesc. 2007;36(3):363-71.

10. Annes A, Redlin M. The careful balance of gender and sexuality: rural gay men, the heterosexual matrix, and "Effeminophobia”. J Homosex. 2012;59(2):256-88.

11. Shidlo A, Schroeder M. Changing sexual orientation: a consumers' report. Prof Psychol. 2002;33(3):249-59.

12. Szymanski DM, Carr ER. The roles of gender role conflict and internalized heterosexism in gay and bisexual men's psychological distress: testing two mediation models. Psychol Men Masc. 2008;9(1):40-54.

13. Bauermeister JA, Connochie D, Jadwin-Cakmak L, Meanley S. Gender policing during childhood and the psychological wellbeing of young adult sexual minority men in the United States. Am J Mens Health. 2017;11(3):693-701.

14. Kashubeck-West S, Szymanksi DM. Risky sexual behavior in gay and bisexual men: internalized heterosexism, sensation seeking, and substance use. Couns Psychol. 2008;36(4):595-614.

15. Maccio EM. Self-reported sexual orientation and identity before and after sexual reorientation therapy. J Gay Lesbian Ment Health. 2011;15(3):242-59.

16. Laemmle J. California's conversion: a ban on minor conversion therapy and the effect on other states. Ind JL Soc Equal. 2013;2:248-70.

17. Haldeman DC. Therapeutic antidotes: helping gay and bisexual men recover from conversion therapies. J Gay Lesbian Psychother. 2002;5(3-4):117-30.

18. Tharinger DJ. Maintaining the hegemonic masculinity through select attachment, homophobia, and gay-baiting in schools: challenges to intervention. School Psychol Rev. 2008;37(2):221-8.

19. Rosario M, Schrimshaw EW, Hunter J. Different patterns of sexual identity development over time: implications for the psychological adjustment of lesbian, gay, and bisexual youths. J Sex Res. 2011;48(1):3-15. 
20. Pearson J, Wilkinson L. Family relationships and adolescent well-being: are families equally protective for same-sex attracted youth? J Youth Adolesc. 2013;42:376-93.

21. Cohler BJ. The experience of ambivalence within the family: young adults "coming out" gay or lesbian and their parents. Contemp Perspect Fam Res. 2004;4:255-84.

22. Jadwin-Cakmak LA, Pingel ES, Harper GW, Bauermeister JA. Coming out to dad: young gay and bisexual men's experiences disclosing same-sex attraction to their fathers. Am J Men's Health. 2015;9(4):274-88.

23. Bauermeister JA, Meanley S, Hickok A, Pingel E, VanHemert W, Loveluck J. Sexuality-related work discrimination and its association with the health of sexual minority emerging and young adult men in the Detroit Metro Area. Sex Res Soc Policy. 2014;11(1):1-10.

24. Meanley S, Gale A, Harmell C, Jadwin-Cakmak L, Pingel E, Bauermeister JA. The role of provider interactions on comprehensive sexual healthcare among young men who have sex with men. AIDS Educ Prev. 2015;27(1):15-26.

25. Graham JW. Missing data analysis: making it work in the real world. Annu Rev Psychol. 2009;60:549-76.

26. Herek GM, Cogan JC, Gillis JR, Gunt EK. Correlates of internalized homophobia in a community sample of lesbians and gay men. J Gay Lesbian Med Assoc. 1998;2:17-26.

27. US Department of Health \& Human Services. 2012 HHS Poverty Guidelines. https://aspe.hhs.gov/2012-hhs-poverty-guidelines . Accessed 7 Aug 2017.

28. Beckstead AL. Cures versus choices: agendas in sexual reorientation therapy. J Gay Lesbian Psychother. 2002;5(3-4):87-115.

29. National Center for Lesbian Rights. \#BornPerfect: The facts about conversion therapy. http://www.nclrights.org/bornperfect-the-facts -about-conversion-therapy/. Accessed 4 Aug 2017.

30. Substance Abuse and Mental Health Services Administration. Ending conversion therapy: supporting and affirming LGBTQ youth. http://store.samhsa.gov/shin/content/ SMA15-4928/ SMA15-4928.pdf. Accessed 4 Aug 2017.

31. Jin F, Jansson J, Law M, et al. Per-contact probability of HIV transmission in homosexual men in Sydney in the era of HAART. AIDS. 2010;24(6):907-13.

32. Preston DB, D'Augelli AR, Kassab C, Starks MT. The relationship of stigma to the sexual risk behavior of rural men who have sex with men. AIDS Educ Prev. 2007;19(3):218-30.

33. Johns MM, Pingel EP, Eisenberg A, et al. Butch tops and femme bottoms? Sexual positioning, sexual decision making, and gender roles among young gay men. Am J Mens Health. 2012;6(6):505-18.

34. Reilly A. Top or bottom: a position paper. Psychol Sex. 2016;7(3):167-76.

35. Harper GW. Sex isn't that simple: culture and context in HIV prevention interventions for gay and bisexual male adolescents. Am Psychol. 2007;62(8):806-19.

36. Reiger G, Linsenmeier JA, Gygax L, Bailey JM. Sexual orientation and childhood gender nonconformity: evidence from home videos. Dev Psychol. 2008;44(1):46-58.

37. Fields EL, Bogart LM, Smith KC, et al. "I always felt I had to prove my manhood": homosexuality, masculinity, gender role strain, and HIV risk among young Black men who have sex with men. Am J Public Health. 2015;105(1):122-31.

38. Wheldon CW, Pathak EB. Masculinity and relationship agreements among same-sex couples. J Sex Res. 2010;47(5):460-70.

39. Beckstead AL. Can we change sexual orientation? Arch Sex Behav. 2012;41(1):121-34.

40. Haldeman DC. Gay rights, patient rights: the implications of sexual orientation conversion therapy. Prof Psychcol. 2002;33(3):260-4.

41. Glick SN, Cleary SD, Golden MR. Increasing acceptance of homosexuality in the United States across racial and ethnic subgroups. J Acquir Immune Defic Syndr. 2015;70(3):319-22.

42. Kane EW. "NO WAY MY BOYS ARE GOING TO BE LIKE THAT!": parents' responses to children's gender nonconformity. Gend Soc. 2006;20(2):149-76.

43. Movement Advancement Project. Conversion therapy laws. http:// www.lgbtmap.org/equality-maps/conversion_therapy. Accessed 17 May 2018.

44. Truth Wins Out. NARTH. https://truthwinsout.org/narth/. 2014. Accessed 14 Feb 2018.

45. Flentje A, Heck NC, Cochran BN. Sexual reorientation therapy interventions: perspectives of ex-ex-gay individuals. J Gay Lesbian Ment Health. 2013;17(3):256-77.

46. Cook JE, Purdie-Vaughns V, Meyer IH, Busch JT. Intervening within and across levels: a multilevel approach to stigma and public health. Soc Sci Med. 2014;103:101-9.

47. Ryan C, Huebner D, Diaz RM, Sanchez J. Family rejection as a predictor of negative health outcomes in White and Latino lesbian, gay, and bisexual young adults. Pediatrics. 2009;123(1):346-52.

48. Doty ND, Willoughby BL, Lindahl KM, Malik NM. Sexuality related social support among lesbian, gay, and bisexual youth. J Youth Adolesc. 2010;39(10):1134-47. 